\section{$N$-Hydroxysuccinimide Ester of Chloromercuriacetic Acid, a New Reagent for Preparing Mercury Derivatives of Amino Acids, Proteins and Aminoacyl Transfer Ribonucleic Acids GEORG FöLSCH}

\section{Department of Medical Biochemistry, University of Göteborg, Sweden}

E sters of $N$-hydroxysuccinimide are $\mathrm{C}_{\text {known }}$ to be convenient and specific reagents for free amino groups of amino acids in the free form as well as when present in macromolecules. ${ }^{1}$ In a search for new methods of preparing heavy-atom derivatives for X-ray-crystallographic investigations of macromolecules and for use as active site directed enzyme reagents we have prepared the $N$-hydroxysuccinimide ester of chloromercuriacetic acid. The latter acid, studied recently by Tilander $^{2}$ was esterified with $N$-hydroxysuccinimide by the method of Anderson et al. ${ }^{1}$

$$
\begin{aligned}
& \mathrm{Cl} \cdot \mathrm{Hg} \cdot \mathrm{CH}_{2} \cdot \mathrm{CO}, \mathrm{H}+\mathrm{HO} \cdot \mathrm{N}\left(\mathrm{CO} \cdot \mathrm{CH}_{2}\right)_{2} \\
& +\mathrm{C}_{6} \mathrm{H}_{11} \cdot \mathrm{N}=\mathrm{C}=\mathrm{N} \cdot \mathrm{C}_{6} \mathrm{H}_{11} \longrightarrow{ }_{\mathrm{CO}-\mathrm{CH}_{2}}^{\longrightarrow}
\end{aligned}
$$$$
+\mathrm{C}_{6} \mathrm{H}_{11} \cdot \mathrm{NH} \cdot \mathrm{CO} \cdot \mathrm{NH} \cdot \mathrm{C}_{6} \mathrm{H}_{11}
$$

The ester was purified by crystallization from 2-propanol and was obtained in more than $90 \%$ yield. The structure of the ester given above was confirmed by mass spectrometry.

The preparation of two derivatives shows that this mercury-containing active ester reacts with a free amino acid, L-valine, as well as with the same amino acid esterifying the $3^{\prime}$ end of valine-specific tRNA. In the latter case it was observed that the chloromercuriacetylation product of L-valyl-tRNA is strongly retarded on a benzoylated DEAE-cellulose column, i.e. as is the case with phenoxyacetylated aminoacyl-tRNA (cf. Gillam et al. ${ }^{1}$ ).

The two chloromercuriacetyl-L-valine derivatives prepared are of interest in studies of the active site of the enzyme valyl transferribonucleic acid synthetase ${ }^{3}$ since most such synthetases are supposed to be sulphydryl enzymes. The reactivity of the mercury-containing active ester towards free amino groups in proteins will be studied separately in connection with X-ray crystallographic studies on the enzyme carbonic anhydrase. ${ }^{4}$

Experimental. Melting points were determined using a Kofler bench. $R_{F}$ values refer to thin-layer chromatography on Kieselgel G. The spots on the plates were detected with the chlorine-iodide-starch reaction. ${ }^{5}$ IR spectra were recorded on samples in the solid state (KBr pellets) using a Perkin-Elmer 157 apparatus. Mass spectra were obtained using an MS 902 instrument (AEI, Manchester). The unit used to quantitize tRNA, $A_{260}$, was defined as the quantity material which dissolved in $1 \mathrm{ml}$ had an absorbance at $260 \mathrm{~nm}$ of 1 with a light path of $1 \mathrm{~cm}$. Assays for ability to form L-valyl-tRNA and enzymatic preparation of the latter were performed by the methods and materials of Lagerkvist et al. ${ }^{3}$

Chloromercuriacetic acid N-hydroxysuccin. imide ester. $N, N^{\prime}$-Dicyclohexyl carbodiimide $(2.05 \mathrm{~g}, 10 \mathrm{mmoles})$ was added to an ice-cold solution of chloromercuriacetic acid ${ }^{2}(2.95 \mathrm{~g}$, $10 \mathrm{mmoles}$ ) and $N$-hydroxysuccinimide $(1.15 \mathrm{~g}$, $10 \mathrm{mmoles})$ in anhydrous dioxane $(60 \mathrm{ml})$. The mixtures were stirred for $3 \mathrm{~h}$ at room temperature, and the precipitate of dicyclohexyl urea (2.1 g, m.p. $230^{\circ}$, decomp.) was removed by filtration. The solution was evaporated to dryness in vacuo and the residue crystallized from 2-propanol. Yield $3.6 \mathrm{~g}(92 \%) ;$ m.p. $172^{\circ} ; R_{F} 0.67$ (1-butanolacetic acid-water, 4:1:1); $R_{F} 0.28$ (light petroleum-tetrahydrofuran-acetic acid 60:40:1). The IR spectrum showed carbonyl absorptions typical for $N$-hydroxysuccinimide esters, with one band at $5.65 \mu$ (ester carbonyl) and a second band of approximately the double intensity at $5.8 \mu$ (succinimide carbonyls). The mass spectrum showed high peaks corresponding to fragments such as:

$$
\begin{aligned}
& m / e=279, \quad\left[{ }^{85} \mathrm{Cl} \cdot{ }^{202} \mathrm{Hg} \cdot \mathrm{CH}_{2} \cdot \mathrm{CO}^{+}\right. \text {and } \\
& \left.{ }^{37} \mathrm{Cl} \cdot{ }^{200} \mathrm{Hg} \cdot \mathrm{CH}_{2} \cdot \mathrm{CO}\right]^{+} ; \\
& m / e=157,\left[\mathrm{CH}_{2} \cdot \mathrm{CO} \cdot \mathrm{O} \cdot \mathrm{N}\left(\mathrm{CO} \cdot \mathrm{CH}_{2}\right)_{2}\right]^{+} \text {; as well }
\end{aligned}
$$

as a series of characteristic molecule ions of $m / e \quad 389-397$, the highest of which had $m / e=393$ (containing ${ }^{85} \mathrm{Cl}^{202} \mathrm{Hg}$ and ${ }^{37} \mathrm{Cl}^{200} \mathrm{Hg}$ ).

$\mathrm{N}$-Chloromercuriacetyl- $\mathrm{L}$-valine. $\mathrm{L}$-Valine (235 $\mathrm{mg}, 2 \mathrm{mmoles}$ ) was dissolved in water $(5 \mathrm{ml})$ and $1 \mathrm{M} \mathrm{NaHCO}(4 \mathrm{ml})$. The solution was cooled to $0^{\circ}$ and a solution of chloromercuriacetic acid $N$-hydroxysuccinimide ester 


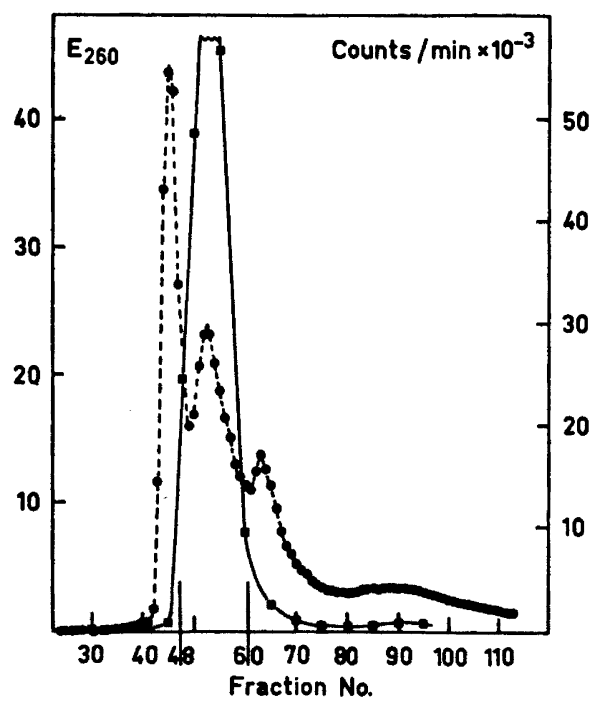

Fig. 1. Chromatography of commercial tRNA on benzoylated DEAE-cellulose. Material eluted with $0.8 \mathrm{M} \mathrm{NaCl}$ (Gillam's Solution B; cf. the text). UV absorption. ${ }^{14} \mathrm{C} \mathrm{cpm}$ obtained in the standard assay for tRNAVal.

(750 $\mathrm{mg}, 2 \mathrm{mmoles}$ ) in anhydrous dioxane (4 ml) was added. The solution was stirred for $2 \mathrm{~h}$ at room temperature. $1 \mathrm{M} \mathrm{HCl}(2 \mathrm{ml})$ was added and the solution evaporated to a small volume in vacuo. Water $(3 \mathrm{ml})$ and $1 \mathrm{M} \mathrm{HCl}(2 \mathrm{ml})$ was added and the crystalline precipitate was collected by filtration, washed with water, and dried in vacuo over $\mathrm{KOH}$. Yield 0.6 g (76 \%), m.p. 230 ${ }^{\circ}$ (decomp.); $R_{F} 0.73$ (1-butanol-acetic acid-water, 4:1:1); $[\alpha]_{D}{ }^{27}+16.5$ (c 4.84 in $N, N$-dimethylformamide). The IR spectrum showed a single carbonyl absorption band at $5.9 \mu$. (Found: $\mathrm{N}$ 3.4. Calc. for $\mathrm{C}_{7} \mathrm{H}_{18} \mathrm{ClHgNO}_{3}$ (394.2): $\mathrm{N} 3.5$ ). Acid hydrolysis of the compound $(5 \mathrm{mg}$ in $1 \mathrm{ml}$ of $6 \mathrm{M} \mathrm{HCl}, 4 \mathrm{~h}, 110^{\circ}$ ) gave valine, identified by thin-layer chromatography.

Chloromercuriacetylation of ${ }^{14} \mathrm{C}-\mathrm{L}_{1}$-valyl$t R N A$ Val. Commercial transfer-ribonucleic acid (tRNA; $1 \mathrm{~g}$ : $15370 \mathrm{~A}_{260}$ units; purchased from Boehringer \& Söhne, Mannheim, Germany) was chromatographed on benzoylated diethylaminoethyl cellulose (BD-cellulose) by the method of Gillam et al. ${ }^{1}$, using a $2.8 \times 85 \mathrm{~cm}$ column. A valine-accepting fraction (7620 $A_{960}$ units) containing most of the tRNA Val present in the starting material was obtained as indicated in Fig. 1. The tRNA was precipitated by adding 3 volumes of cold ethanol and a part of it (2740 $A_{260}$ units) was then esterified enzymatically with ${ }^{14} \mathrm{C}$-L-valine $\left(14.9 \mathrm{mC} / \mathrm{mmole} ; 23.3 \times 10^{6} \mathrm{cpm} / \mu \mathrm{mole}\right)$ in the presence of valyl transfer-ribonucleic acid synthetase, and the mixture of ${ }^{11} \mathrm{C}$-L -valyltRNAVal and unesterified bulk tRNA isolated again by ethanol precipitation. This precipitate $\left(12.2 \times 10^{6} \mathrm{cpm}\right.$ corresponding to $520 \mathrm{~m} \mu$ moles of ${ }^{14} \mathrm{C}-L_{\text {--valine) }}$ was dissolved in $7 \mathrm{ml}$ of $0.1 \mathrm{M}$ triethanolamine-HCl buffer of $\mathrm{pH}$ 4.3 and containing $0.01 \mathrm{M} \mathrm{MgCl}_{2}$, and was

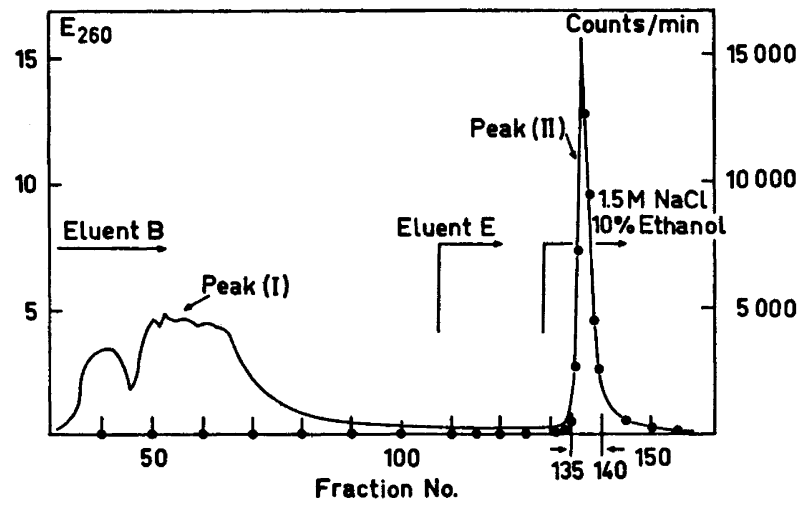

Fig. 2. Chromatography on benzoylated DEAE-cellulose of tRNA esterified with ${ }^{14} \mathrm{C}$-I,-valine and treated with chloromercuriacetic acid $N$-hydroxysuccinimide ester. For complete description of eluents, see Gillam et al. ${ }^{1}$ and the text. —— UV absorption. ${ }^{14} \mathrm{C}$ radioactivity. 
reacted at pH 8 with a solution of $200 \mathrm{mg}$ chloromercuriacetio acid $N$-hydroxysuccinimide ester in $1 \mathrm{ml}$ of anhydrous tetrahydro. furan, as described for the corresponding phenoxyacetylation procedure (Gillam et al.1) The reaction product isolated by ethanol precipitation was dissolved in $10 \mathrm{ml}$ of Gillam's 1 solution $A$ and was applied (2800 $A_{260}$ units, $11.4 \times 10^{6} \mathrm{cpm}$ ) to the previously mentioned BD-cellulose column. The column was eluted with Gillam's solutions A, B, E, and finally with $1.5 \mathrm{M} \mathrm{NaCl}$ solution containing $10 \%$ ethanol, $0.01 \mathrm{M} \mathrm{MgCl}$ and $0.01 \mathrm{M}$ sodium acetate buffer pH 4.5. The chromatogram obtained is shown in Fig. 2. It is evident from the figure, that non-radioactive material, i.e. unesterified tRNA is eluted with the solution $B$ at the same position as in Fig. 1 (peak (I)). No ${ }^{14} \mathrm{C}$-valyl-tRNA seems to be present in the product, since we have found such aminoacyl-tRNA to be eluted with the solution $B$ immediately after the unesterified tRNA.

The material eluted with $1.5 \mathrm{M} \mathrm{NaCl}$ should be chloromercuriacetylated ${ }^{14} \mathrm{C}$-valyl-tRNA because of its coinciding UV-absorption and radioactivity, and because of the similar high affinity to the column that has been found for all $N$-acylated aminoacyl-tRNA:s studied by Gillam et al. ${ }^{1}$

The fraction (II) indicated in Fig. 2 was precipitated by 3 volumes of ethanol, collected by centrifugation and dissolved in $4 \mathrm{ml}$ of water. This solution contained $310 A_{200}$ units (560 $\mathrm{m} \mu$ moles, calculated with the value of $1.8 \mathrm{~m} \mu$ moles tRNA per $A_{280}$ units $^{6}$ ) and $10.2 \times 10^{6} \mathrm{cpm}(440 \mathrm{~m} \mu \mathrm{moles})$ giving a ratio tRNA $/{ }^{14} \mathrm{C}$-L,-valine of 1.27 .

Acknowledgements. The author is indebted to Professor Ulf Lagerkvist for guidance and support in the tRNA part of this work, to Miss Vaike Kask and Mrs. Monica Olsson for technical assistance and to Dr. Bengt Andersson for running the mass spectra. The investigation was supported by a research grant from the Swedish Medical Research Council (B 70-13X-175-06B).

1. Anderson, G. W., Zimmerman, J. E. and Callahan, F. M. J. Am. Chem. Soc. 86 (1964) 1839; Lapidot, Y., De Groot, N., Weiss, M., Peled, R. and Wolman, Y. Biochim. Biophys. Acta 138 (1967) 241; Lapidot, Y., Rappoport, S. and Wolman, Y. J. Lipid Res. 8 (1967) 142; Gillam, I., Blew, D., Warrington, R. C., von Tigerstrom, M. and Tener, G. M. Biochemistry 7 (1968) 3459.

Acta Chem. Scand. 24 (1970) No. 3
2. Tilander, B. Arkiv Kemi 25 (1966) 459.

3. Lagerkvist, U. and Rymo, L. J. Biol. Chem. 244 (1966) 2476 and previous papers.

4. Strandberg, B. Arkiv Kemi 28 (1967) 1; Fridborg, L., Kannan, K. K., Liljas, A., Lundin, J., Strandberg, B., Strandberg, R., Tilander, B. and Wirén, G. J. Mol. Biol. 25 (1967) 505.

5. Rydon, H. N. and Smith, P. W. G. Nature 169 (1952) 922.

6. Holley, R. W., Everett, G. A., Madison, J. T. and Zamir, A. J. Biol. Chem. 240 (1965) 2122.

Received March 24, 1970.

\section{Naphthylmethylseleno-substituted Alkanoic Acids ARNE FREDGA}

Department of Organic Chemistry, Chemical Institute, University of Uppsala, P.O.Box 531, S-751 21 Uppsala 1, Sweden

Tn the course of current work on the 1 biological effects of organoselenium compounds the acids I, II and 18 homologues (Tables 1 and 2) have been prepared. The end in view was to test the growthregulating activity, the factor-3-effect and<smiles>O=C(O)C[Se]CC[Se]Cc1ccc2ccccc2c1</smiles>

possibly other biological effects. The work on the growth-regulating activity, which also included some acids with selenium attached directly to the naphthalene ring prepared in this institute, ${ }^{1,2}$ was carried out by Professor B. A Aberg.* It has in part been published ${ }^{2-4}$ and indicates that the selenium compounds have an antiauxin effect, more pronounced than that of the corresponding sulphur compounds. The acid II is perhaps the most powerful anti-auxin known."

* Royal Agricultural College, Uppsala, Sweden. 